\title{
Intake Screening with the Self-Rating Depression Scale in a University Counseling Center
}

\author{
Timothy B. Smith \\ Brigham Young University, tbs@byu.edu \\ llene Rosenstein \\ University of Pennsylvania \\ Michael M. Granaas \\ University of South Dakota
}

Follow this and additional works at: https://scholarsarchive.byu.edu/facpub

Part of the Counseling Psychology Commons

\section{Original Publication Citation}

Smith, T. B., Rosenstein, I., \& Granaas, M. (2001). Intake screening with Self-Rating Depression Scale in a university counseling center. Journal of College Counseling, 4, 133-141.

\section{BYU ScholarsArchive Citation}

Smith, Timothy B.; Rosenstein, llene; and Granaas, Michael M., "Intake Screening with the Self-Rating Depression Scale in a University Counseling Center" (2017). Faculty Publications. 1995.

https://scholarsarchive.byu.edu/facpub/1995 
Running Head: ZUNG DEPRESSION SCALE

Smith, T. B., Rosenstein, I., \& Granaas, M. (2001). Intake screening with Self-Rating Depression Scale in a university counseling center. Journal of College Counseling, 4, 133-141.

Intake Screening with the

Self-Rating Depression Scale

in a University Counseling Center

Timothy B. Smith

Brigham Young University

Ilene Rosenstein

Counseling and Psychological Services

University of Pennsylvania

Michael Granaas

University of South Dakota 


\begin{abstract}
Screening clients at intake for symptoms of depression can be beneficial, provided the instrument used is reliable and valid. The psychometric properties of the Self-Rating Depression Scale (SDS) were examined using an ethnically diverse sample of 324 counseling center clients. Results provided moderate support for the SDS. Differences across demographic groups and considerations for intake screening are discussed.
\end{abstract}


Intake Screening with the

\section{Self-Rating Depression Scale}

in a University Counseling Center

Students who present for services at college counseling centers commonly report symptoms of depression (e.g., Gallagher, Christophidis, Gill, \& Weaver-Graham, 1996; Sakamoto, Kijima, Tomoda, \& Kambara, 1998). Students with symptoms of depression are at risk for multiple negative outcomes, including academic failure, medical complications, and suicide (e.g., Weber, Metha, \& Nelson, 1997). The prevalence and potential severity of depression makes this condition a particularly salient concern for mental health professionals to address. Nevertheless, when a student presents at a college counseling center with a concern seemingly unrelated to depression, such as career concerns, symptoms of depression may not be reported and thus are not noticed. Research results show that depression is often undetected (e.g., Attkison \& Zich, 1990). To reduce the risk of overlooking potentially significant symptoms of depression among student clients, college counseling centers may wish to administer a brief screening instrument at intake.

Screening clients at intake for symptoms of depression may reduce the risk of a subsequent major depressive episode (Munoz, Le, \& Ghosh Ippen, 2000). Specifically, screening can (1) identify clients who experience symptoms of depression but may not verbally report feeling “depressed,” (2) reduce or eliminate time spent on a waiting list for clients whose need for treatment appears urgent, (3) successfully triage clients with more severe pathology to the most experienced or specialized counselors within the center (4) increase referrals for external treatment and/or psychiatric evaluation for medication, and (5) provide baseline data useful for tracking a client's progress in treatment. When systematically conducted across all 
clients, the latter benefit of tracking client progress can also validate the quality of counseling services on college campuses (Nafziger, Couillard, \& Smith, 1999; Steenbarger \& Smith, 1996), which have experienced increasing fiscal and administrative pressures in recent years to report outcome data on clients and services to justify continued funding (Corazzini, 1997; Gallagher et al., 1996).

Despite the apparent benefits, some professional counselors may have reservations about the usefulness of paper and pencil assessments or about the additional resources that screening requires (i.e., the cost of test administration, time spent scoring and interpreting the results). (e.g., Steenbarger \& Smith, 1996). Some counseling centers, for fiscal reasons, may have developed their own intake form that includes limited information pertinent to severity of a client’s presenting concerns related to depression. However, utilizing a "home-made” symptom checklist or screening instrument is not to be confused with use of a reliable and valid screening assessment for detecting depression. Multiple assessment tools with proven psychometric properties have been reported in the literature, some of which are free for professional use.

One such widely used instrument is the Self-Rating Depression Scale (SDS) (Zung, 1965). The SDS was developed using clinical diagnostic criteria to assesses common symptoms of depression that are grouped under three categories: pervasive affect, physiological equivalents, and psychological concomitants. The instrument consists of 20 items that are scored on a fourpoint scale, thus indicating the frequency of a given symptom. Possible responses range from "None or a little of the time" to "Most or all of the time." Half of the items are worded as symptomatically positive; the other half are expressed as symptomatically negative and are reverse scored. The SDS has demonstrated adequate reliability and validity within a wide variety of adult clinical samples. The SDS has correlated highly with other standardized measures of 
depression, including the MMPI depression scale and the Beck Depression Inventory (BDI), and estimates of internal consistency with the SDS have ranged from .78 to .92, with the average estimate being approximately .87 (e.g., Dugan et al., 1998; Griffin \& Kogut, 1988; Lane, Shellenberger, Gresen, \& Moore, 2000; Schaefer et al., 1985; Zung, 1965). In regards to criterion validity, the SDS has been shown to be superior to the BDI when matching clinicians’ ratings of client depression and when differentiating adult psychiatric inpatients with major depression from those with more mild forms of depression (Griffin \& Kogut, 1988; Schaefer et al., 1985). The SDS has been widely used to screen adult inpatients and outpatients for the presence of major depression across multiple settings (Dugan et al., 1998; Lane et al., 2000).

A general limitation of assessment tools such as the SDS is that many remain unvalidated among college student clients. According to Tanaka and Huba (1987) and others, this population differs from adult clinical samples of clients, particularly as related to education level and academic achievement. A similar but more pervasive limitation is that few assessment tools have been validated with samples representative of people of color, thus making interpretation of results with people of color problematic (D. W. Sue \& Sue, 1999; S. Sue, 1999). The purpose of this research study was to investigate the psychometric properties of the SDS using a racially diverse sample of college student clients and to draw generalizations for college counseling centers that screen clients for symptoms of depression.

Method

All students who presented for services at a counseling center at a mid-sized urban university completed the SDS at intake, along with demographic questionnaire. Archival data for the study were extracted from charts of clients who had been in counseling during the most recent academic year. 
In order to ensure that students of color were adequately represented in the research sample, participants were stratified by race so that half were Caucasians randomly selected from among all clients. This stratified sampling procedure ensured that the remaining half of the sample included a minimum of 70 African Americans and 70 Asian Americans. Thus representation of people of color was increased to provide adequate statistical power for analyses across race. As indicated, past studies have typically not analyzed results by race, or they have included samples not representative of people of color. This is problematic from the perspective of statistical power and external validity (Sue, 1999). The selection procedure utilized in this study increases the statistical conclusion validity and the external validity of the results. Due to limited numbers on this particular campus, other racial groups were not included in the sample.

The resulting sample of 324 students included 165 (51\%) Caucasians, 73 African Americans (23\%), and 86 Asian Americans (26\%). Of these, 212 (65\%) were women and 112 (35\%) were men; 200 (62\%) were undergraduates, and 124 (38\%) were graduates. The average age was 22.6 years ( $\underline{\mathrm{SD}}=4.5) ; 84(26 \%)$ of the sample were 18 or 19 years old, 111 (34\%) were 20 to 22, 79 (25\%) were 23 to 26,32 (10\%) were 27 to 30, and $17(5 \%)$ were over 30. The number of sessions attended past intake ranged from 1 to 45 , with most students attending between 2 and 10 sessions $(\underline{\mathrm{M}}=5, \underline{\mathrm{SD}}=5)$. Diagnostic assessments indicated that 50 clients (15\%) met criteria for a major depressive disorder, 75 (23\%) met criteria for an adjustment disorder, 29 (9\%) met criteria for an anxiety disorder, 14 (4\%) met criteria for dysthymia, 7 (2\%) met criteria for bi-polar depression, 42 (13\%) met criteria for a variety of other moderate to severe mental health conditions, such as eating disorders or personality disorders, and 107 (33\%) experienced comparatively minor difficulties associated with a DSM-IV V-code. With the 
exception of race, as noted above, these demographics were representative of clients typically seen at the counseling center

Several techniques were used to analyze the data. Descriptive statistics revealed the distribution of the data. To evaluate the psychometric properties of the SDS with the current sample, we calculated estimates of scale reliability and ran a confirmatory factor analysis to test the expected three-factor solution (Sakamoto et al., 1998; Zung, 1965). A discriminant function analysis tested the assumption that intake screening with the SDS correctly identified clients diagnosed with major depression. Analyses of variance (ANOVAs) were conducted to evaluate potential differences in responses to SDS items across the demographic groups of race, gender, and undergraduate/graduate status.

Results

\section{$\underline{\text { Preliminary Analyses }}$}

Preliminary analyses were conducted to ensure that the data did not violate any statistical assumptions. Descriptive analyses revealed that all but 2 of the 20 SDS items showed distributions approximating the normal curve. Item 8, “I have trouble with constipation,” and Item 19, "I feel that others would be better off if I were dead,” had positively skewed (2.5 and 3.1 respectively) and unusually leptokurtic distributions (kurtosis $=6.1$ and 10.3 respectively). Kurtosis is a minor problem under normal test usage; however in this case it suggests a clear lack of variability in these items that could unduly affect the results of statistical analyses. A correlation matrix of SDS items revealed that Item 2, "Morning is when I feel the best," was not statistically significant when correlated with 18 of the other 19 SDS items. Thus, items 2, 8, and 19 were removed from the results of the factor analysis reported below. 


\section{$\underline{\text { SDS Factor Structure }}$}

A confirmatory factor analysis was conducted to test the construct validity of the SDS. Based on prior research on depression measures (Byrne, 1995) and on the SDS in particular (Sakamoto et al., 1998; Zung, 1965), this model included a single second order factor (depression) and three first order factors (affective, somatic, and psychological symptoms of depression; see Figure 1).

The chi-square fit for this model was significant $\left(\chi_{116}^{2}=274.2, p<.001\right)$, suggesting a lack of fit in the model. However, other fit indices indicated only minor problems with the model's fit to these data $(\mathrm{NNFI}=.89$ and $\mathrm{CFI}=.90)$. Further inspection of these data did indicate a possible problem with kurtosis (normalized kurtosis estimate of 11.6), which could account for the lack of fit in the chi-square results.

$\underline{\text { SDS Reliability and Criterion Validity }}$

The full scale reliability coefficient (alpha) was .87 with this sample. When the problematic Items 2, 8, and 19 were removed, analyses with the resulting 17-item scale yielded a reliability coefficient of .87 (indicating that the reduced form was equivalently reliable to the full SDS). The reliability estimate of .87 remained the same across racial groups, across genders, and across undergraduate/graduate status.

The ability of the SDS to predict a diagnosis of major depression was examined as an indicator of criterion validity. A discriminant function analysis revealed that SDS items correctly predicted clients with a diagnosis of major depression vs. all other presenting conditions $87 \%$ of the time (Wilks Lambda $=.83$, Chi-square $=53.2, p<.001$ ). When data from the 7 clients diagnosed with bi-polar depression and the 14 clients diagnosed with dysthymia were grouped 
with the 50 diagnosed with major depression, 86\% of cases were correctly identified (Wilks Lambda $=.84$, Chi-square $=50.3, p<.001)$.

\section{Demographic Differences}

A one-way ANOVA performed across racial groups indicated that Asian Americans scored higher on the SDS than did Caucasians $(\underline{F}=3.8, \underline{p}=.02)$. Item-level analyses indicated that Asian Americans endorsed 5 of the 20 SDS items (8, 10, 17, 18, and 19) more than Caucasians (Item 8, $\underline{F}=4.4, \underline{p}=.01 ;$ Item $10, \underline{F}=4.2, \underline{p}=.02 ;$ Item $17, \underline{F}=5.2, \underline{p}=.006$; Item $18, \underline{\mathrm{F}}=4.7, \underline{\mathrm{p}}=.01 ;$ Item $19, \underline{\mathrm{F}}=4.3, \underline{\mathrm{p}}=.015)$. These five items assess somatic and affective aspects of depression. Item analyses also indicated that African Americans differed from the other two groups on only one item: Number 12, "I find it easy to do the things I used to do" ( $\underline{F}=$ $4.7, \underline{p}=.01)$.

Analyses conducted across gender revealed that women scored higher than men on 4 of the 20 SDS items (3, 5, 6, and 16) that assess affective and psychological aspects of depression (Item 3, $\underline{\mathrm{F}}=51.1, \underline{\mathrm{p}}<.0001 ;$ Item 5, $\underline{\mathrm{F}}=5.7, \underline{\mathrm{p}}=.03$; Item $6, \underline{\mathrm{F}}=11.1, \underline{\mathrm{p}}=.001 ;$ Item $16, \underline{\mathrm{F}}=8.3$, $\mathrm{p}=.004)$. Analyses conducted across student status showed that undergraduates scored higher than graduates on three items that assess psychological aspects of depression: Number $2(\underline{F}=$ 5.2, $\underline{\mathrm{p}}=.02)$, Number $6(\underline{\mathrm{F}}=4.2, \underline{\mathrm{p}}=.04)$, and Number $12(\underline{\mathrm{F}}=5.7, \underline{\mathrm{p}}=.02)$.

\section{Discussion}

Due to the prevalence and potential severity of mental health conditions, such as depression, counseling centers sometimes administer clinical instruments to screen for those conditions to facilitate client treatment. Clinical assessment and screening devices developed with predominantly Caucasian adult clinical samples are used routinely in counseling centers without adequate understanding of their application with college students, and particularly with 
students of color. The results of this study provide additional information on the use of the SDS as a reliable and valid screening tool for symptoms of depression among students across three racial groups. However, some analyses raised issues warranting additional attention.

The results indicated that SDS Item 2 (“Morning is when I feel the best”) was problematic with this sample of college student clients: The modal response indicated severe disturbance, but these scores did not correlate with depression. This finding is likely unique to undergraduate college student samples due to their typical socializing and sleep schedules (graduate students scored lower on this item). Hence, the scores on this item can be minimized or disregarded with undergraduate college student samples, since its presence will inflate Type I errors. For interpretation purposes, the score on this item can be corrected to " 1 " when summing the raw score, if such an adjustment appears warranted.

The results of this study also indicated that even though the SDS was equally as reliable and valid across demographic groups; however, Asian American and women participants were more likely to have higher mean scores on the SDS than were Caucasian and men participants. Similar results have been found in other studies (Crittenden, Fugita, Bae, Lamug, \& Lin, 1992; de Jonghe \& Baneke, 1989). Asian Americans may tend to endorse somatic symptoms and women may tend to endorse affective and psychological symptoms when reporting on their own mental health (e.g., Sue \& Sue, 1999). Nevertheless, these culturally sanctioned propensities to self-report symptoms in specific areas may not actually translate into higher levels of pathology. Because it is not known to what degree these mean score differences reflect measurement error, bias in test construction, or valid distribution patterns, interpretation of scores from Asian American participants on the somatic items and female participants on the affective and psychological items should be slightly more conservative than global norms would indicate. 


\section{Limitations of this Study}

Despite their potential usefulness of these results, the study is subject to several limitations. Although the sample size was adequate, participants were selected from only one university, thus limiting the external validity of the findings. A second limitation is that data is reported using only one screening instrument, the SDS. While the SDS is easy to administer and is psychometrically adequate, results of this study should in no way be considered an endorsement for the SDS as a single screening tool. Multiple similar instruments are available for screening that may serve as adequately as the SDS, if not more adequately. What is recommended overall is that college counseling centers conduct client screening on a regular basis, using a screening instrument with adequate psychometric support. It is suggested that findings of the present study will benefit from future studies using alternative assessment devices and participant samples truly representative of racial diversity.

\section{$\underline{\text { Implications for College Counseling Centers }}$}

Routine use of a screening assessment at intake in college counseling centers may yield multiple benefits. Identification of clients who are potentially at-risk for a severe condition such as major depression can improve the quality of treatment by triaging those clients to experienced or specialized counselors, reducing their potential delay on a waiting list, and increasing external referrals for treatment or medication. Furthermore, data collected at intake can be used to track changes in a client's symptoms over time, which can facilitate effective treatment and which can be aggregated with other data to assess the outcome of counseling services. Results of this study emphasize that the realization of these potential benefits depends upon the psychometric properties of the instrument used. Some screening instruments are more accurate and consistent than others. Few have been developed specifically for use in college counseling centers, and few 
have adequate normative data with college clients or with people of color. However, as shown by the results of the present study, instruments developed with predominantly adult Caucasian clinical samples can sometimes prove reliable and valid in other settings and with other groups of people. Results also show, however, that attention to psychometric properties must be a major consideration in selecting an appropriate screening instrument for college populations.

The benefits of screening enumerated above also are contingent upon accurate interpretation of scores. For example, the results of this study suggested modifications in the interpretation of an item found to be problematic with undergraduate student clients. Knowing the psychometric properties of an instrument with a specific population makes such interpretation modifications possible.

Similarly, the results of this study indicated that client demographics such as gender and race should be taken into account when interpreting screening scores. Assessments of women and people of color should provide interpretations representative of their particular contextual patterns of symptom expression (Sue \& Sue, 1999). Normative data for specific populations sought in the research literature or collected in-house can facilitate accurate interpretation of scores obtained in screening assessments used in college counseling centers.

Interpretation of assessment results can also benefit from the identification of subscales in a particular instrument. This study confirmed the finding that the SDS essentially comprises three subscales: affective, somatic, and psychological (Figure 1). Interpretation of subscales makes it possible to identify different profiles of symptoms, such as clients who emphasize psychological over affective disturbances. For example, knowing that somatic symptoms of depression assessed by the SDS highly overlap with anxiety disorders (e.g., Mineka, Watson, \& Clark, 1998) can aid interpretation and target subsequent assessments and treatment. 
Due to the prevalence and potential severity of untreated depression (Munoz et al., 2000), screening clients for relevant symptoms can improve the standard of mental health services in college counseling centers. However, it should be kept in mind that using a single screening instrument that is specific to one disorder, such as the SDS is specific to depression, may result in a large number of Type II errors for other serious mental health conditions. Clients with severe symptoms not directly related to depression (e.g., eating disorders) may not be identified. When multiple severe conditions are common or when a more comprehensive screening is possible, a counseling center may wish to select a screening instrument that assesses either global mental health, such as the Outcome Questionnaire - 45 (OQ-45) (Lambert et al., 1996), or a range of problems typical of college student populations, such as the College Adjustment Scales (Anton \& Reed, 1991). Optimally, screening should be done in two stages, wherein the paper and pencil instrument is scored and followed immediately by a diagnostic interview. Nevertheless, if a college counseling center has yet to implement systematic client screening or if circumstances prevent a more comprehensive screening procedure, it is strongly recommended that assessment of clients' levels of depression begin at intake - at minimum (Munoz et al., 2000; Weber et al., 1997). 


\section{References}

Anton, W. D., \& Reed, J. R. (1991). College adjustment scales: Professional manual.

Odessa, FL: Psychological Assessment Resources, Inc.

Attkisson, C. C., \& Zich, J. M. (Eds.). (1990). Depression in primary care: Screening and detection. New York: Routledge.

Byrne, B.M. (1995). One application of structural equation modeling from two perspectives. In R. H. Hoyle (Ed.), Structural equation modeling: Concepts, issues, and applications. Thousand Oaks, CA: Sage.

Corazzini, J. G. (1997). Using research to determine the efficacy and modes of treatment in university counseling centers: Comment on Jobes, Jacoby, Cimbolic, and Hustead (1997) and Hayes (1997). Journal of Counseling Psychology, 44, 378-380.

Crittenden, K., Fugita, S., Bae, H., Lamug, C., \& Lin, C. (1992). A cross-cultural study of self-report depressive symptoms among college students. Journal of Cross-Cultural Psychology, $\underline{23}, 163-178$.

de Jonghe, J., \& Baneke, J. (1989). The Zung Self-Rating Depression Scale: A replication study on reliability, validity, and prediction. Psychological Reports, 64(3), 833-834.

Dugan, W., McDonald, M., Passik, S., Rosenfeld, B., Theobald, D., \& Edgerton, S. (1998). Use of the Zung Self-Rating Depression Scale in cancer patients: Feasibility as a screening tool. Psycho-Oncology, 7, 483-493.

Gallagher, R.P., Christofidis, A., Gill, A., \& Weaver-Graham, W. (1996). National survey of counseling center directors. Alexandria, VA: International Associations of Counseling Services, Inc.. 
Griffin, P. T., \& Kogut, D. (1988). Validity of orally administered Beck and Zung depression scales in a state hospital setting. Journal of Clinical Psychology, 44, 756-759.

Lambert, M. J., Hansen, N. B., Umpress, V., Lunnen, K., Okiishi, J., \& Burlingame, G. M. (1996). Administration and scoring manual for the OQ-45.2. Stevenson, MD: American Professional Credentialing Services.

Lane, J., Shellenberger, S., Gresen, K., \& Moore, N. (2000). Screening for depression within a rural primary care practice by a self-rating depression scale. Primary Care Psychiatry, 6(2), 73-76.

Mineka, S., Watson, D., \& Clark., L. (1998). Comorbidity of anxiety and unipolar mood disorders. Annual Review of Psychology, 49, 377-412.

Munoz, R. F., Le, H., \& Ghosh Ippen, C. (2000). We should screen for major depression. Applied \& Preventative Psychology, 9, 123-133.

Nafziger, M., Couillard, G., \& Smith, T. B. (1999). Evaluating therapy outcome at a university counseling center. Journal of College Counseling, 2, 3-13.

Sakamoto, S., Kijima, N., Tomoda, A., Kambara, M. (1998). Factor structures of the Zung Self-Rating Depression Scale (SDS) for undergraduates. Journal of Clinical Psychology, 54, 477-488.

Schaefer, A., Brown, J., Watson, C., Plemel, D., DeMotts, J., Howard, M., Petrik, N., Ballenweg, B., \& Anderson, D. (1985). Comparison of the validities of the Beck, Zung, and MMPI depression scales. Journal of Consulting and Clinical Psychology, 53, 415-418.

Steenbarger, B. N., \& Smith, H. B. (1996). Assessing the quality of counseling services: Developing accountable helping systems. Journal of Counseling and Development, 75, 145-150. 
Sue, D. W., \& Sue, D. (1999). Counseling the culturally different: Theory and practice (3 ${ }^{\text {rd }}$ ed.). New York: Wiley.

Sue, S. (1999). Science, ethnicity, and bias: Where have we gone wrong? American Psychologist, 54, 1070-1077.

Tanaka, J. S., \& Huba, G. J. (1987). Assessing the stability of depression in college students. Mutivariate Behavioral Research, 22, 5-19.

Weber, B., Metha, A., \& Nelsen, E. (1997). Relationships among multiple suicide ideation risk factors in college students. Journal of College Student Psychotherapy, 11(3), 49-64. 
Figure 1.

Confirmatory Factor Analysis of the SDS.

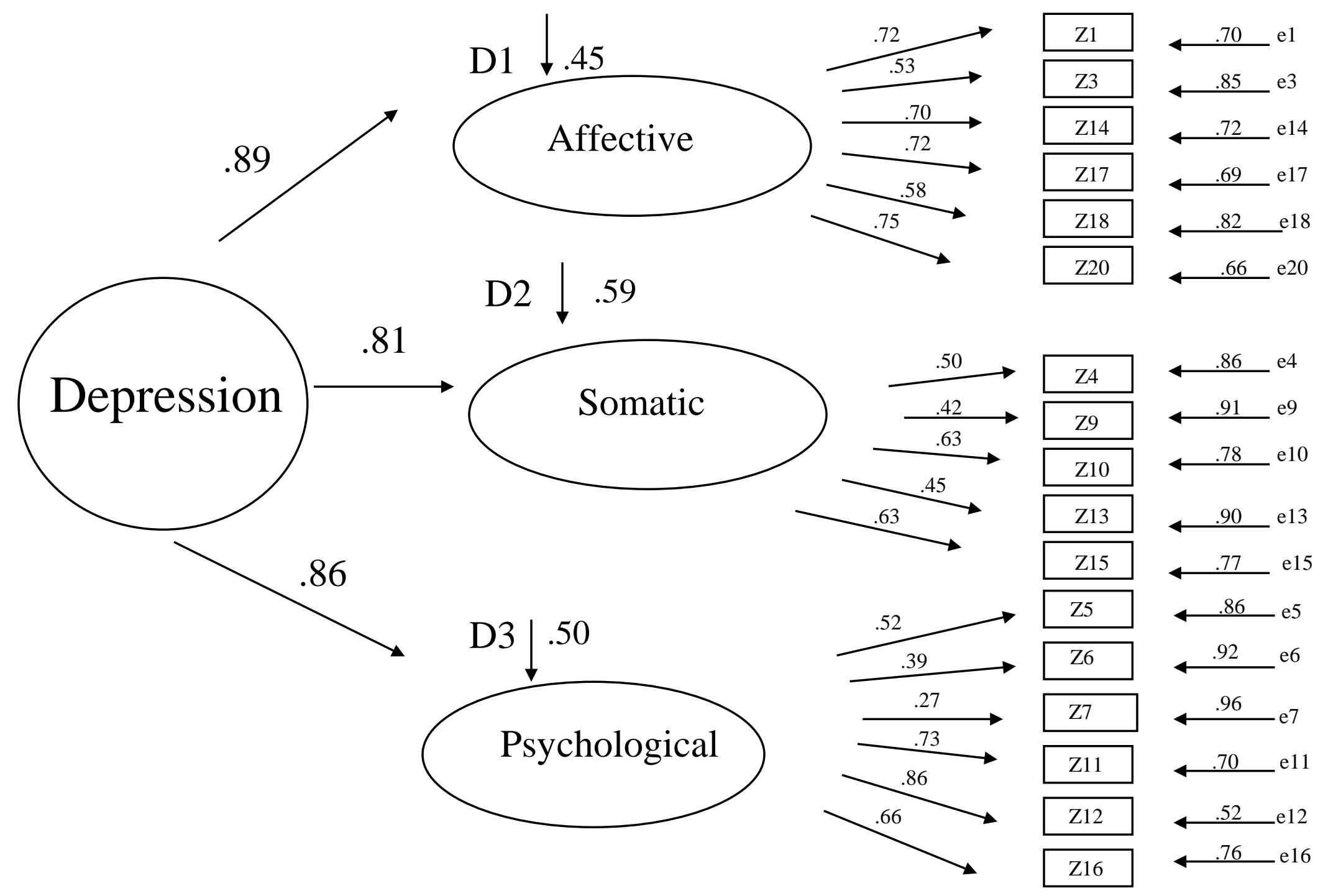


